\title{
EDUCAÇÃO DO CAMPO E PRÁTICAS PEDAGÓGICAS: RELAÇÕES DE TRABALHO EM COMUNIDADES AMAZÔNICAS
}

\author{
EDUCACIÓN SOBRE EL TERRENO Y PRÁCTICAS PEDAGÓGICAS: RELACIONES \\ LABORALES EN COMUNIDADES AMAZÓNICAS
}

\author{
FIELD EDUCATION AND PEDAGOGICAL PRACTICES: WORKING \\ RELATIONSHIPS IN AMAZONIC COMMUNITIES
}

\author{
Arminda Rachel Botelho MOURÃO ${ }^{1}$ \\ Luciene Mafra VANCONCELOS ${ }^{2}$ \\ Iraci Carvalho UCHÔA ${ }^{3}$
}

RESUMO: O artigo movimenta discussões sobre a contextualização histórica do município de Careiro da Várzea (AM), a política de Educação do Campo e as relações de trabalho em comunidades amazônicas. A análise constrói-se com base nas categorias Careiro da Várzea, Sujeitos Amazônicos, Trabalho e Educação do Campo, valendo-se da Pesquisa-Ação e revisões bibliográficas. Partindo-se da compreensão que adota o trabalho como categoria fundante da existência dos sujeitos, articulando-o à concepção de educação do campo. Articulam-se tais conceitos e o artigo possibilita perceber que a educação do campo enquanto política não se materializa no município, contudo, a concepção é efetivamente construída mediante as relações do trabalho.

PALAVRAS-CHAVE: Careiro da várzea. Trabalho. Educação do campo. Sujeitos amazônicos.

RESUMEN: El artículo mueve las discusiones sobre la contextualización histórica del municipio de Careiro da Várzea (AM), la política de educación rural y las relaciones laborales en las comunidades amazónicas. El análisis se basa en las categorías Careiro da Várzea, Subjects Amazánicas, Trabalho y Educao do Campo, utilizando Action Research y revisiones bibliográficas. Partiendo del entendimiento que adopta el trabajo como una categoría fundadora de la existencia de los sujetos, articulando a la concepción de la educación del campo. Estos conceptos se articulan y el artículo nos permite percibir que la educación del campo como una política no se materializa en el municipio, sin embargo, la concepción se construye efectivamente a través de las relaciones de trabajo.

\footnotetext{
${ }^{1}$ Universidade Federal do Amazonas - (UFAM), Manaus - AM - Brasil. Professora titular do programa de pósgraduação e coordenadora do GT: Genêro, Trabalho e Educação. ORCID: https://orcid.org/0000-0002-19409477. E-mail: irauchoa100@ outlook.com

${ }^{2}$ Universidade Federal do Amazonas - (UFAM), Manaus - AM - Brasil. Técnico administrativo da universidade e pesquisadora do GT: Gênero, Trabalho e Educação. ORCID: https://orcid.org/0000-0002-7376-2423. E-mail: lucienemafra.ufam@gmail.com

${ }^{3}$ Universidade Federal do Amazonas - (UFAM), Manaus - AM - Brasil. Doutoranda do PPGE/UFAM e pesquisadora do GT: Gênero, Trabalho e Educação. ORCID: https://orcid.org/0000-0003-1794-924X. E-mail: irauchoa100@outlook.com
} 
PALABRAS CLAVE: Careiro de tierras bajas. Trabajo. Educación sobre el terreno. Súbditos amazónicos.

ABSTRACT: The article moves discussions on the historical contextualization of the municipality of Careiro da Várzea, the field education policy and work relations in an Amazon community. The analysis is constructed based on the categories Careiro do Várzea, Amazonian Subjects, Labor and Field Education, based on Action Research and bibliographic reviews. Starting from the understanding that adopts work as a founding category of the existence of the subjects articulating it the conception of education of the field. The concepts are articulated and it makes it possible to realize that the education of the field as a policy is not materialized in the municipality, however, the conception is effectively constructed from the relations of work.

KEYWORDS: Littleland's careiro. Work. Education of the field. Amazonian subjects.

\section{Introdução}

O texto que apresentamos é resultado da pesquisa intitulada "Tempo Comunidade da Especialização em Educação do Campo Práticas Pedagógicas”, que foi oferecida aos formadores do Programa Escola da Terra, às organizações dos Movimentos Sociais e aos professores da Rede Municipal de Ensino da Secretaria Municipal de Educação (SEMED). A Especialização foi realizada em dois momentos, denominados respectivamente o Tempo Universidade e o Tempo Comunidade, e apoiou-se nos pressupostos metodológicos da Pesquisa-Ação. Esses momentos possibilitaram movimentar discussões sobre a contextualização histórica do município de Careiro da Várzea (AM), a política de Educação do Campo e suas relações com a categoria trabalho em comunidades amazônicas.

Ao discutir e problematizar as relações de trabalho, identificamos que são construídas com base na organização coletiva da agricultura familiar camponesa. Essa organização articula-se à concepção da política de Educação do Campo, uma vez que representa os anseios da classe trabalhadora, já que foi gestada por meio da luta e resistência dos Movimentos Sociais.

Para Benjamin \& Caldart (2000), o trabalho produz cultura, e os trabalhadores, mediante sua organização e luta pela superação das condições de alienação que historicamente os caracterizaram como sujeitos excluídos de quaisquer formas de direito, constituem a classe trabalhadora. Na gama dos direitos pelos quais eles empenham-se, a educação pública gratuita e socialmente referenciada é uma bandeira primordial. Não obstante, o alcance da educação pública socialmente referenciada ocorrerá a partir do 
momento em que os governantes brasileiros se conscientizarem de que a educação deve ser prioridade das políticas públicas (DOURADO; OLIVEIRA, 2009).

O trabalho no contexto amazônico é permeado tanto por meio da contradição do Modo de Produção Capitalista quanto por meio da Dialética da natureza. Essa contradição se evidencia nos processos produtivos das relações assalariadas; já a dialética da natureza ocorre pelo processo da subida e descida das águas, movimento constante em que o trabalhador constrói e reconstrói as relações sociais.

Pistrak (2011) defende que o trabalho enquanto base da educação deve estar ligado ao trabalho social, à produção real, a uma atividade concreta e socialmente útil. Em relação a tais fatores, a Educação do Campo relaciona-os aos processos produtivos da agricultura familiar camponesa, defendendo o trabalho como base principal do projeto educativo da escola, o qual deve vincular os conhecimentos escolares ao mundo do trabalho e da cultura por ele produzida, participando das lutas de superação da forma histórica que o trabalho assume na sociedade capitalista (BENJAMIN; CALDART, 2000).

Ao longo das investigações identificou-se que o trabalho coletivo integra a rotina das populações que retiram da natureza a sua existência (SILVA, 2014). Tais sujeitos dedicam-se à Agricultura Familiar Camponesa, que abarca diversas categorias de trabalhadores, dentre as quais: ribeirinhos, caiçaras, extrativistas, pescadores, indígenas, remanescentes de quilombos, assentados ou em processo de assentamentos. Esses camponeses vivem do trabalho coletivo e têm suas atividades centradas no núcleo familiar.

Em torno desse tema, este artigo tem como objetivo geral analisar as relações de trabalho no município do Careiro da Várzea, com base em práticas pedagógicas no período da Especialização em Educação do Campo. Os objetivos específicos são: a) identificar a organização de trabalho e contextualizar a história do município; b) analisar a organização do trabalho, no contexto amazônico, percebendo suas relações com a concepção de Educação do Campo.

As categorias Careiro do Várzea, Trabalho, Educação do Campo e Sujeitos amazônico são as que alicerçam o texto, que foi elaborado seguindo os pressupostos do primeiro eixo articulador do Tempo Comunidade da Especialização.

A pesquisa é o instrumento de investigação usado pela ciência para gerar novos conhecimentos. Demo (1987, p. 23) a define como “[...] a atividade pela qual descobrimos a realidade". A pesquisa científica "[...] é uma investigação sistemática, controlada, empírica e crítica de proposições hipotéticas sobre supostas relações entre fenômenos naturais" (KERLINGER, 1973, p. 11), de tal modo que consiste na etapa inicial de todo trabalho 
científico ou acadêmico, com o objetivo de reunir as informações e dados que servem de base à construção de determinado tema.

Quanto aos procedimentos técnicos de que nos valemos na investigação, utilizamos a Pesquisa-Ação e Bibliográfica. Segundo Gil (2008), a diferença entre a pesquisa bibliográfica e a documental está na natureza das fontes, pois esta forma reune materiais que não receberam ainda um tratamento analítico, ou que ainda podem ser reelaborados de acordo com os objetos da pesquisa. Como instrumentos de coleta de dados utilizamos o Caderno de Campo. O texto está organizado em duas seções. Na primeira, contextualizamos a história do município e o apresentamos como território de trabalho. Na segunda, abordamos a organização de trabalho percebendo suas relações com a concepção de Educação do Campo no contexto amazônico e, por fim, apresentamos as considerações.

\section{Educação do Campo e Práticas Pedagógicas: um relato através do olhar de uma formadora da Especialização em Educação do Campo}

Os tempos comunidades realizados no município de Careiro da Várzea permitiram as socializações das práticas pedagógicas e, por consequência, o contato com a realidade local, de modo que os objetivos da pesquisa foram construídos com a finalidade de potencializar a análise da relação do homem do campo com o seu espaço e o seu papel no território.

Os períodos dos tempos comunidades se deram com base na matriz pedagógica, organizada em 4 (quatro) eixos articuladores ligados aos eixos temáticos, e culminou no seminário integrador. O seminário propiciou a socialização das práticas pedagógicas de professores do campo, tema abordado em três momentos. No primeiro Tempo Comunidade, houve discussão a respeito de Lutas e o Trabalho no Campo, refletindo sobre Estado e Políticas Públicas em Educação do Campo; Sociologia do Trabalho e Movimentos Sociais do Campo; Agricultura Familiar, Desenvolvimento Sustentável e Alfabetização Agroecológica.

No segundo Tempo Comunidade, foram discutidos os Fundamentos da Educação do Campo, abarcando os aspectos Epistemológicos da Educação do Campo; Metodologia da Pesquisa em Educação; Escola Politécnica e Elementos Educativos; Pedagogia HistóricaCrítica e Prática Social. No terceiro Tempo Comunidade, foram retomados os seguintes Eixos Articuladores: Educação do Campo na Amazônia, História, Geografia e o Patrimônio Cultural da Amazônia; Pedagogia da Alternância e os Procedimentos Teóricos e Metodológicos.

As teorias discutidas nos tempos comunidades entre formadores e cursistas possibilitaram que o trabalho pedagógico da Educação do Campo fosse realizado mediante a 
ação-reflexão-ação, e por meio dessa dinâmica abriu-se caminho a uma nova reflexão e consequentemente uma nova práxis, relatadas pelos cursistas a cada encontro formativo.

O último encontro culminou com o Seminário Integrador, iniciado pela manhã, e nele participaram professores das escolas do campo, formadoras da Universidade Federal do Amazonas (UFAM), pais e mães de alunos e os comunitários. A socialização das pesquisas realizadas no Seminário foi feita aos estudantes das escolas de classes multisseriadas, teve início com a execução do Hino Nacional, em seguida a mística simbolizou os desafios do professor do campo na região Amazônica, e, ao final, foram proferidos agradecimentos e felicitações aos cursistas pelas pesquisas realizadas.

Durante as formações, mediante relatos dos cursistas e trocas de experiências da lida diária de cada um, temas foram problematizados proporcionando categorizar a política de educação do campo no município e a organização do trabalho, pois ainda que sejam oferecidos programas que representam avanços a fim de agregar concepções de superação do sujeito, a política de educação do campo não é implementada no contexto do município.

\section{Contextualização histórica versus Território de Trabalho}

A história do território do Careiro da Várzea data da década de 1930, em função do Decreto Lei $\mathrm{n}^{\mathrm{o}} 176$ de 1 de dezembro de 1938 que dispõe sobre a divisão territorial do Brasil, estabelecendo os distritos da cidade de Manaus. O ano de 1938 é marcado pelo golpe militar liderado por Getúlio Vargas, que instaurou o período ditatorial conhecido como Estado Novo (REGO; MARQUES, 2014), cujas bases foram posteriormente um elemento de influência ao projeto de desenvolvimento da Amazônia. Nessa ordem sociopolítica, a Constituição de 1946 trouxe para os municípios amazônicos a possibilidade de uma elevação econômica com a instituição do plano de valorização da Amazônia, além de "estabelecer conceitos para a administração pública municipal, principalmente no que se refere à arrecadação dos tributos de competência local e à participação da arrecadação federal via Imposto de Renda" (DUTRA; PEREIRA, 2018), e nesse contexto, em 1955 foi desmembrado o território de Careiro da Várzea, sendo elevado à categoria de município de Manaus.

Segundo informações dos moradores antigos do município, a denominação de Careiro foi adquirida em função de que naquela região existia um comércio que pertencia a Francisco, um morador antigo que costumava vender os produtos acima dos valores considerados pelo mercado. Por isso, a população sempre reclamava: “Aqui é careiro" (NOGUEIRA, 2007). Essa informação é reconhecida pelos professores cursistas em formação, quando retratam o 
contexto histórico do município de Careiro da Várzea ao socializar atividades no Tempo Universidade, em que debatem sobre políticas públicas em Educação do Campo.

Não obstante, a construção do território do município data do período da colonização da Amazônia. Há notícias de que desde 1774 a região era conhecida e chamada por seus primitivos habitantes, Uaquiri (STERNBERG, 1998). Ao retornar ao passado, Silva (2014) salienta que a expedição de Francisco Orellana desceu os rios Solimões-Amazonas em 1542, tendo feito descrições da adaptabilidade das populações humanas na região.

O município situa-se a $20 \mathrm{~km}$ a Sul-Leste de Manaus. A área de várzea ocupada fica entre 10 e 25 quilômetros e apresenta duas unidades geomorfológicas distintas. Uma é a planície de bancos e meandros atuais, que corresponde à faixa de sedimentos arenosos que o rio deposita por meio de migração lateral. A outra é o depósito de inundação, formado por áreas planas e homogêneas, com lagos de tamanhos diversos. Careiro da Várzea está distante de Manaus, partindo do Porto da Ceasa, aproximadamente 45 minutos, numa viagem de carro. O município no período de cheia tem cerca de $80 \%$ de sua área inundada, pois está distribuído às margens dos rios Solimões-Amazonas (NOGUEIRA, 2007).

O Careiro da Várzea mantém, em seus $2.642 \mathrm{~km}$ quadrados, a maior ilha da região, a Ilha do Careiro, cuja extensão é de $738 \mathrm{~km}$ quadrados. A pesca, a agricultura, a criação de animais de pequeno porte e a criação do gado leiteiro são suas principais atividades econômicas. A Ilha do Careiro possui mais de 62 lagos de pesca.

É neste contexto que se deu a construção do município e ali se formaram os cenários dos trabalhadores que têm as comunidades como Unidades de Produções. Segundo o censo do Instituto Brasileiro de Geografia e Estatística (IBGE, 2010), existem 107 comunidades no campo e aproximadamente 22.930 habitantes, o que indica uma quantidade expressiva de moradores nas zonas rurais, ao passo que, na zona urbana, há em torno de 1.000 habitantes. Em 2007, havia 17 mil habitantes, sendo que 700 habitantes residiam na sede do município e 16.300 habitantes no campo (NOGUEIRA, 2007).

Tendo como parâmetros os dados estatísticos do IBGE, que registra o aspecto populacional do município, em seis anos houve relativo aumento da população urbana, contudo, a maior parte continua nas zonas rurais, onde residem os povos que nas festas populares e religiosas de Nossa Senhora do Perpétuo Socorro, Festa do Repolho e Festival do Queijo expressam suas mais diversificadas culturas e identidades.

A forma como é constituída a caracterização do município é resquício de uma cultura ruralista que tem como finalidade a exploração do trabalhador. Essa forma de pensar é o 
reflexo do Estado no papel de controlador das decisões por meio do mecanismo de criação da mais-valia (MOURÃO, 2014).

Tais situações refletem nas políticas públicas instituídas para o campo, visto que as condições de trabalho desses sujeitos não interessam à lógica produtivista, destacando-se apenas o interesse de baratear a força de trabalho. É interessante realçar a função dominadora do Estado, seja na providência de políticas públicas para promover o bem comum, seja no seu limite de abster-se, quando se trata de respeitar as liberdades dos indivíduos.

No município de Careiro da Várzea, as políticas para o trabalho no campo do município, ainda que tenham a Assistência do Instituto de Desenvolvimento Agropecuário e Florestal Sustentável do Estado do Amazonas (IDAM), que fomenta materiais e equipamentos agrícolas (exemplos, forno para casa de farinha, rabeta, kit ferramenta e kit pescador), não é suficiente, pois não atende à demanda do município, já que apenas 446 famílias são beneficiadas.

\section{A organização de trabalho dos protagonistas amazônicos}

Ao longo da história, o ser humano vem criando diferentes modos de se relacionar com a natureza. Historicamente, o processo do trabalho era considerado o momento fundamental para compartilhar saberes e conhecimentos construídos ao longo das gerações, pois o mesmo garantia a forma de existência das comunidades (MOURÃO, 2014).

Fundamentalmente, o trabalho era o momento para dividir os aprendizados que perpassavam gerações, organização compartilhada que se tornou uma das características da região amazônica, pois relaciona-se ao trabalho coletivo da agricultura familiar camponesa (UCHÔA; MOURÃO, 2018). Com base nesses pressupostos compreende-se que o trabalho da agricultura familiar está ligado à "Educação do Campo, pois a mesma combina com Reforma Agrária, com agricultura camponesa [...], e tem um vínculo de origem com as lutas sociais do campo" (CALDART et al, 2004, p. 20).

No transcorrer do desenvolvimento das sociedades, esse trabalho se metamorfoseia, e hoje existem diferentes tipos de trabalho, dos quais os incentivos dependem dos interesses da classe dominante. É nesse emaranhado de contradições que os povos tradicionais lutam constantemente para não sucumbirem diante do Capital, reivindicando políticas educacionais que representam os anseios dos trabalhadores. 
Os professores das comunidades ribeirinhas do município do Careiro da Várzea que participaram das atividades do Tempo Universidade da Especialização em Educação do Campo, evidenciaram que há o trabalho coletivo nas seguintes atividades:

a) Produção de farinha;

b) Cultivo de hortaliças;

c) Plantio de pupunha, macaxeira, jerimum e melancia;

d) Cultivo do maracujá;

e) Mutirão de ajuda para construção de casas ou para fazer o plantio;

f) Pesca.

A ideia de apropriação e produção da cultura, ao longo da história da humanidade, tem sido concebida com base na transmissão de conhecimentos e de valores repassados de uma geração para outra por meio do ato de ensinar e aprender.

A cultura que passou de geração a geração está viva e precisa ser valorizada. Destacamos que no campo as relações de trabalho são construídas, e também no campo o trabalhador se constrói historicamente no trato com a natureza e por meio da comunicação entre membros de famílias distintas, quando se narram fatos do cotidiano, experiências na agricultura e na pesca, planejam-se atividades sociais, comerciais, entre outras (WITKOSKI, 2010).

A terra, a floresta e a água participam de modo decisivo da forma como esses agentes sociais procuram dar plenitude à vida (WITKOSKI, 2010). No campo, as atividades são divididas de acordo o trabalho coletivo da família. Crianças, jovens e adultos desempenham funções de acordo com a realidade da comunidade. Nesse contexto, o trabalho da criança é visto como natural, embora seja considerado por muitos um trabalho ilegal, mas naquele território integra as culturas dos sujeitos amazônicos. O trabalho eleva o homem e lhe traz alegria; educa o sentimento coletivo, enobrece o homem, e é por isso que o trabalho, e particularmente o trabalho manual de qualquer tipo, é necessário como meio de educação" (PISTRAK, 2011, p. 39).

As crianças e os jovens, sejam dos sexos masculino ou feminino, participam das atividades de plantio, tratos culturais e colheita, nos processos de trabalho que utilizam técnicas tradicionais ou não. Ao chefe da família cabe a responsabilidade da socialização destinada ao mundo do trabalho. Depois de ter realizado os trabalhos na agricultura, algumas tarefas domésticas ficam a cargo da esposa e outras da filha mais velha que, por exemplo, prepara a alimentação familiar e cuida dos irmãos menores (WITKOSKI, 2010). 
Os dados revelaram que no Careiro da Várzea pode-se relacionar a teoria descrita por esse autor com a realidade dos camponeses no que se refere às atividades desenvolvidas no campo das comunidades. A seguinte pergunta foi direcionada aos professores em formação: Como são divididas as atividades de trabalho entre homens, mulheres, jovens e crianças na comunidade? Diversas respostas foram obtidas, dentre elas estão:

a) Os homens ficam com o trabalho mais pesado e as mulheres com o trabalho mais leve;

b) Os homens fazem o trabalho de provedor e as mulheres cuidam das casas, as crianças e os adolescentes ajudam nos afazeres;

c) O trabalho é dividido coletivamente.

Destaca-se o protagonismo da mulher trabalhadora que tem suas responsabilidades para além dos afazeres da agricultura familiar, visto que nos trabalhos considerados mais leves incluem-se as tarefas de manutenção e estrutura familiar. O território da várzea e da terra firme é o lócus dos camponeses (WITKOSKI, 2010). A questão que o autor sugestiona é: Como se dá o envolvimento do camponês amazônico com essa extensão de terra, floresta e água?

Ao relacionar a teoria e a prática, entendemos que as relações de trabalho no campo ocorrem de modos variados, uma vez que para os professores em formação do município do Careiro da Várzea elas podem ser:

a) Assalariada e temporária;

b) Cooperativista;

c) Em forma de benefícios de Bolsa Família e Aposentadoria.

O campo, enquanto território de vida, historicamente tem sido o cenário de trabalho. Esse trabalho tem estreita relação com a herança cultural das primeiras comunidades tribais, em que "[...] não se tinha divisão de classes sociais e todos estavam em pé de igualdade no processo de produção coletiva” (MOURÃO, 2014, p. 23). Estas relações estão presentes em algumas comunidades do campo do Careiro da Várzea, pois, ao categorizar as respostas dos questionários, identificou-se a organização coletiva dos processos produtivos regionais.

A Agricultura Familiar Camponesa se contrapõe ao Modo de Produção Capitalista, e não se apoia nos princípios da propriedade privada. Ao contrário, ela favorece os pequenos agricultores e trabalhadores que retiram da natureza o essencial para uma vida no campo, permitindo-lhes melhor qualidade de vida, preservando o meio ambiente, e a valorização cultural (SILVA, 2014). E, particularmente, relaciona-se à concepção de Educação do Campo, reforça a dimensão pedagógica da organização coletiva e enfatiza a reflexão da cultura no 
processo histórico, associando questões do processo de aprendizagem e ensino (BORGES, 2015).

Mourão (2014) ressalta que as relações no campo são contraditórias, pois os sujeitos estão inseridos no Modo de Produção Capitalista. Com base nas concepções marxistas, Uchôa \& Mourão (2018) salientam que, nesse modo de produção, o poder se concentra nas mãos de uma pequena minoria e o trabalhador torna-se escravo do trabalho, e é nesse contexto que observam-se as relações assalariadas de trabalho no campo como um processo inerente ao Capital. Desse modo, concluímos que, no campo do Careiro da Várzea, as relações de trabalho podem ser coletivas e assalariadas.

Nesse contexto, o eixo de trabalho da agricultura familiar nas comunidades e a sua organização se faz por meio das cooperativas. Discutir a especificidade da agricultura camponesa "[...] é importante no cotejo com o campo ideológico da agricultura capitalista, que insiste na afirmação da diferença entre atrasado e moderno e nunca na contraposição" (JESUS, 2005).

Tendo como base esse entendimento, é mais viável para a classe dominante considerar atrasada a Agricultura Familiar Camponesa do que subsidiar recursos para o seu fortalecimento, isso porque o modo camponês de produzir e de viver está em contradição com o Capital. Ao mesmo tempo, faz-se necessário o alargamento da autonomia dos camponeses em relação ao capital, a fim de que avance a construção atual da agricultura camponesa (BENJAMIN; CALDART, 2000).

Para os professores em formação do Careiro da Várzea a Agricultura Familiar se fortalece por meio de:

a) Cooperativas da Agricultura Familiar;

b) O trabalho mais coletivo em parceria com as comunidades;

c) Em articulação com a Agência de Fomento do Estado do Amazonas (AFEAM) e o Serviço Brasileiro de Apoio às Micro e Pequenas Empresas (SEBRAE).

De acordo com a estimativa do IBGE (2018), a população do Careiro da Várzea é de 29.595 habitantes. O jornal A crítica (2018) destaca que a verba destinada à produção agrícola para o corrente ano seria de aproximadamente $\mathrm{R} \$ 74.600,00$, beneficiando 100 produtores, fato que nos faz depreender que os recursos não atendem à demanda de todos. Na longa história do capitalismo no mundo "[...] sua forma de agricultura nunca conseguiu substituir ou superar a agricultura camponesa, que continua sendo pilar fundamental da produção de alimentos (BENJAMIN; CALDART, 2000). 
É na dialética da natureza caracterizada pela subida e descida das águas que o camponês, em sua unidade de produção, cultiva as diversificadas culturas (WITKOSKI, et al, 2014). No tempo das enchentes é o momento da colheita dos produtos e a seca representa o momento do semear. Para o autor, uma das características da identidade do camponês é o respeito pela natureza, e pode ser percebida no momento do pousio, período que o camponês deixa a terra descansar para ser utilizada no ano seguinte.

As estratégias econômicas das populações de várzeas do Médio-Baixo Amazonas combinam com as principais atividades: a pesca, a agricultura, a criação de gado. A agricultura é a atividade mais comum entre as populações que dependem de recursos da várzea, e dentre os produtos da agricultura familiar camponesa estão a banana, o cacau, a laranja e a mandioca (SILVA, 2014). O trabalho no campo é de suma relevância - é preciso reconhecê-lo e igualmente aos hábitos e práticas nele envolvidos que assumem grande estatura na cultura amazônica - e a Educação do Campo não se materializa dissociada desta categoria, em virtude de o trabalho ser a base fundante da existência dos sujeitos. De fato, há um movimento dialético entre trabalho e educação do campo que se sustenta por meio do protagonismo dos trabalhadores.

$\mathrm{Na}$ agricultura familiar camponesa, os produtos são cultivados em um campo que se contrapõe ao latifúndio, e é este um conceito primordial da Educação do Campo (UCHÔA \& MOURÃO, 2018). A Educação do Campo vincula-se às causas, aos desafios, aos sonhos, à História e à Cultura do povo trabalhador do campo, portanto, é uma educação do e no campo, que se constrói pelos sujeitos e pelas suas organizações. (ARROYO et al, 1999).

Conforme a pesquisa, os produtos cultivados pelos trabalhadores do município do Careiro da Várzea são: a mandioca e consubstancialmente a produção da farinha, o plantio do maracujá e da banana, da goiaba, do milho, da abóbora, da batata, do maxixe, do quiabo, e da criação de gado regional para a alimentação das famílias da região.

Retomando ao objetivo geral de discorrer sobre a contextualização histórica do município de Careiro da Várzea/Amazonas, a política de Educação do Campo e suas relações com a categoria trabalho em uma comunidade amazônica, salientamos que os processos de construção histórica do município relacionam-se ao desenvolvimento do Modo de Produção Capitalista, tendo em vista a sua expansão nos territórios periféricos.

Esse é um movimento que reflete nas relações de trabalho e dita quais concepções de educação devem ser instituídas. A Educação do Campo é gestada mediante a organização dos Movimentos Sociais e por esse motivo está estreitamente vinculada ao trabalho no campo, em que o território se contrapõe à monocultura e nesse sentido é o campo das múltiplas culturas e 
múltiplas identidades, que requer diálogos capazes de permitir a sua visibilidade enquanto território de existência de um povo.

\section{Considerações finais}

As culturas tradicionais, os gestos e os modos milenares que passaram de geração a geração estão presentes na vida do homem amazônico, exemplo disso é o modo como o camponês conduz o trabalho da agricultura familiar, articulando a força de trabalho do homem, da mulher e da criança, tanto no âmbito do respeito mútuo em cada grupo como diante da natureza.

Se entendemos o trabalho como a categoria fundante da existência humana, igualmente precisamos avaliar que as políticas públicas educacionais devem ser construídas por esses sujeitos. É nesse contexto que percebemos e valorizamos a Educação do Campo, uma política que se construiu em função do protagonismo e da resistência dos movimentos sociais que se manifestam contra quaisquer formas de desrespeito à classe trabalhadora. No entanto, é necessário enfatizar que, embora a educação do campo seja uma política pública conquistada, ela não é implementada em todos os territórios, em razão de se constituir como uma categoria em disputa entre Capital e Trabalho.

No transcorrer do desenvolvimento das sociedades, o trabalho metamorfoseou-se (LESSA, 2007), passando por mudanças em conformidade com os interesses das classes dominantes. Em consequência, os sujeitos passaram a vender sua força de trabalho por valores diminutos, que mal dão conta de suas despesas, com os quais apenas podem sobreviver. Considerando essa perspectiva de análise, entendemos que na atualidade existem diferentes formas de organização do trabalho em que as condições são determinadas em função dos interesses do Modo de Produção.

Ao analisar a Educação do Campo e as relações de trabalho em uma comunidade amazônica, ainda que ela seja uma política educacional conquistada, não há, no entanto, sua implementação, uma vez que o Modo de Produção capitalista se impõe, em todos os níveis da sociedade, excluindo os que não são de seu interesse. No caso da Amazônia, esse processo de exclusão ocorre tanto pelo fato de ser o território dos sujeitos amazônidas como pelo fato de ser uma das periferias do Capital (HARVEY, 2011).

As políticas que visam melhores condições de vida do trabalhador não ocorrem por boas intenções do Estado, mas pela luta dos movimentos sociais. É nesse cenário de 
exploração que os povos tradicionais lutam constantemente para não sucumbirem diante dos interesses do Grande Capital.

No campo, as relações de trabalho são diversificadas. No conjunto desta diversificação pode ser encontrada a interferência do Modo de Produção Capitalista nas relações de trabalho assalariadas, resquícios de uma cultura ruralista que visa a exploração do homem amazônico.

É possível identificar as estratégias desta exploração quando os incentivos destinados ao trabalho no campo não atendem as demandas locais e regionais. Cerca de $70 \%$ da base alimentar das famílias brasileiras é proveniente da Agricultura Familiar Camponesa, contudo, as demandas de investimentos que potencializam esta prática são insuficientes, pois o incentivo é dado ao agronegócio, cujo objetivo é produzir para exportação e, desse modo, canalizar recursos para o desenvolvimento econômico.

Tal movimento pode revelar um posicionamento crítico e ideológico quando se trata de trabalho e educação do campo. Nesse sentido, ele segue na contramão de toda e qualquer forma de exclusão que inviabilize a autonomia e o protagonismo dos sujeitos, que têm sido prejudicados em consequência do atraso na implementação de políticas educacionais, exatamente ali naqueles contextos em que o trabalho do campo ocorre com base num modo coletivo de viver.

Ao final desta análise, ressaltamos que o trabalho no campo amazônico reveste-se de legitimidade e pode, em seus processos de organização, articular-se com a concepção de educação do campo, numa perspectiva de retomada de posição em que se efetive uma educação no campo e do campo capaz de dialogar e representar os anseios dos trabalhadores amazônicos.

\section{REFERÊNCIAS}

ARROYO, M. G. et al. A educação básica e o movimento social do campo. Brasília, DF: Articulação Nacional Por Uma Educação Básica do Campo, 1999.

CALDART, R. S. et al. Contribuições para a construção de um projeto de educação do campo. Brasília, DF: Coleção Por Uma Educação Básica do Campo, 2004.

DEMO, P. Introdução à metodologia da ciência. 2 ed. São Paulo: Atlas, 1987.

DOURADO, L. F.; OLIVEIRA, J. F. A qualidade da educação: perspectivas e desafios. Cad. CEDES, v. 29, n. 78, p. 201-215, maio/ago. 2009. Disponível em:

http://www.scielo.br/scielo.php?pid=S010132622009000200004\&script=sci_abstract\&tlng=pt. Acesso em: 23 abr. 2019. DOI: https://doi.org/10.1590/S0101-32622009000200004 
DUTRA, M. J. de L.; PEREIRA, H. dos S. Formação de municípios no Amazonas após a Constituição Federal de 1946: fragmentos de uma história interrompida e esquecida. Ver. Bras. Estud. Urbanos Reg, São Paulo, v. 20, n. 1, p. 51-68, jan./abr. 2018. Disponível em: http://www.scielo.br/scielo.php?script=sci_abstract\&pid=S231715292018000100051\&lng=pt\&nrm=iso. Acesso em: 27 jun. 2019. DOI: https://doi.org/10.22296/2317-1529.2018v20n1p51

GIL, A. C. Como elaborar projetos de pesquisa. 4 ed. São Paulo: Atlas, 2008.

HARVEY, D. O Enigma do Capital: e as crises do capitalismo. Tradução de João Alexandre Peschanski. São Paulo, SP: Boitempo, 2011.

Instituto Brasileiro de Geografia e Estatística. Aspectos físicos e geográficos. 2010.

Disponível em: https://cidades.ibge.gov.br/brasil/am/careiro-da-varzea/panorama. Acesso em: 08 nov. 2018.

JESUS, E. L. Diferentes abordagens de agricultura Não-Convencional: História e Filosofia. In: Agroecologia Princípios e Técnicas para uma agricultura orgânica sustentável. Embrapa Informação Tecnológica, Brasília, DF 2005. Disponível em: https://www.agencia.cnptia.embrapa.br/recursos/AgrobCap1ID-Sim092KU5R.pdf. Acesso em: 1 nov. 2019.

KERLINGER, F. N. Foundations of behavioral research. In: New York: Holt, Rinehart \&Winston 1973. Disponível em: http://www.ebah.com.br. Acesso em: 30 out. 2017.

LESSA, S. Mundo dos homens: trabalho e ser social. São Paulo: Instituto Lukács, 2012.

MOURÃO, A. R. B. Trabalho como princípio educativo. In: Borges, H. da S. (Orgs.).Trabalho e educação do/no campo: Agricultura familiar, agroecologia e alfabetização ecológica: Manaus: EDUA, 2014. p. 56-68.

NOGUEIRA, A. B. Lugar e Cultura: a produção da vida no Careiro da Varzea-AM. In: Revista ACTA Geográfica, Roraima, v. 1, n. 2, jul./dez. 2007, p. 85-95. Disponível em: https://revista.ufrr.br/index.php/actageo/article/view/183. Acesso: 20 maio 2019.

PISTRAK, M. M. Fundamentos da escola e do trabalho. São Paulo: Expressão Popular, 2011.

REGO, J. M.; MARQUES, R. M. Economia Brasileira. São Paulo: Saraiva, 2013.

SILVA, C. A. Área de interface ceramista pretérita: a coleção arqueológica José Alberto Neves. Orientador: Eduardo Góes Neves. 2014. 211 f. Tese (Doutorado em Sociedade e Cultura) - Universidade Federal do Amazonas, Manaus, 2014. Disponível em: https://tede.ufam.edu.br/handle/tede/5219. Acesso em 28 fev. 2020.

STERnBerg, H. O. R. A Água e o Homem na Várzea do Careiro. Belém: Museu Paraense Emílio Goeldi,1998. 
UCHÔA, I. C.; MOURÃO, A. R. B. Trabalho e Educação do campo no contexto Amazônico: um estudo em uma comunidade camponesa do médio Rio Solimões. Orientadora: Arminda Rachel Botelho Mourão. 2018. 133f. Dissertação (Mestrado em Educação) - Universidade Federal do Amazonas, Manaus, 2018. Disponível em: https://tede.ufam.edu.br/handle/tede/6378. Acesso em 28 fev. 2020.

WITKOSKI, A. C., et al. Território e Territorialidade na Amazônia: Formas de Sociabilidade e Participação Política. Manaus: Editora Valer, 2014.

WITKOSKI, A.C. Terras, Florestas e águas de Trabalho: os camponeses amazônicos e as formas de uso de seus recursos naturais. São Paulo: Annablume, 2010.

\section{Como referenciar este artigo}

MOURÃO, Arminda Rachel Botelho; UCHÔA, Iraci Carvalho; VANCONCELOS, Luciene Mafra. Educação do campo e práticas pedagógicas: relações de trabalho em comunidades mazônicas. Revista Ibero-Americana de Estudos em Educação, Araraquara, v. 15, n. 2, p. 436-450, abr./jun. 2020. e-ISSN: 1982-5587. DOI: https://doi.org/10.21723/riaee.v15i2.12642

Submetido em: 05/03/2019

Revisões requeridas: 10/06/2019

Aprovado em: 20/10/2019

Publicado em: 20/02/2020 